\title{
Design for Mitigating Urban Heat Island: Proposal of a Parametric Model
}

\author{
Begüm Sakar* \\ Olgu Çalışkan**
}

\begin{abstract}
Urban areas dramatically affect the microclimatic conditions of cities, and induce the 'Urban Heat Island' (UHI) effect, which generates many undesirable conditions in the living environment. In recent years, several studies have been examined a strong correlation between the morphology of urban areas and the development of heat island intensity. Then the increasing need for climate responsive design approaches calls for the development of new methodical approaches and tools to control the planned (trans)formation of the urban fabrics. Computational modelling techniques, in this context, suggest relevant methodologies to provide an evidence-based design approach to the issue. This research, in this regard, aims to propose a parametric model for analyzing the key morphological components of urban tissues with regards to the UHI intensity on the basis of 'Sky View Factor' (SVF) while testing the alternatives in generative manner. The proposed (parametric) model, therefore, stands on the close-correlation between the algorithmic simulation based on the selected parameters and morphological analysis. By the model, SVF values of the different building settings are calculated with reference to the basic building codes of the development planning system in Turkey (i.e. FAR, building height and setback) in an actual context. Then the proposed model is tested in the case of one of
\end{abstract}

Keywords: Evidence-based urban design, parametric modelling, urban heat island, urban morphology

*METU Faculty of Architecture, Department of City and Regional Planning, Ankara, Turkey ORCID

Email: begumsakar@gmail.com

**Assoc. Prof. Dr. METU Faculty of Architecture, Department of City and Regional Planning, Ankara, Turkey ORCID /corresponding author

Email: olgucaliskan@gmail.com

This paper is based on the MSc thesis entitled 'Parametric Modelling For The Mitigation of Urban Heat Island Effect: A Model Proposal' that was conducted within METU Master of Urban Design (MUD) Program in 2018. 
the transformation areas in Ankara, Turkey. Eventually, a methodical framework is aimed for a climate responsive urban design process to mitigate urban heat island.

\section{INTRODUCTION}

Urban climate is a key factor of urban livability which is influenced by the complexity of morphological characteristics (form and geometry) which, in turn, condition the thermal properties of urban surfaces. The intrinsic physical nature of the cities as the cumulative outcome of long-term (trans)formation, results in the emergence of the particular urban microclimatic conditions in the cities. Defined as the measured differentiation in the air temperature between urban areas and its surroundings, the phenomenon of Urban Heat Island (UHI) is considered one of the major issues on the spatial performance of urban morphology. Emerging environmental problems due to an increase in the UHI effect in urban areas call for a specification of the influential factors on the change in the thermal balance of the environment as an outcome of urban development.

Urban geometry as the main factor in the development of heat island intensity, in this regard, has been evaluated by several studies by which its critical effects have been proved for recent years. Accordingly, the variation on the main parameters of urban geometry, (i.e. location, orientation, height of the buildings and spaces between them) has been specified to define the correlation between urban form and the ambient air temperature. In those studies, sky view factor (SVF), which is based on the degree of visibility of sky from the ground level, is used to simulate urban canyons, which are characterized by horizontal (street) and vertical (building surfaces) elements of the urban fabric.

To specify the real effect of the indicators of urban geometry on UHI, many studies have been conducted on the actual urban areas by using certain computational tools. Since those models have largely focused on measuring various conditions of UHI in different urban contexts, the lack of predictive tools for the simulation of UHI intensity has emerged in the research field. Need for the test-scenarios, estimations based on the specific urban areas, and the practical restrictions on form generation by computational design tools, so far, call for the development of new tools and techniques that would enable designers and planners to build a proactive perspective on the climate-responsive urban design.

Since the development of parametric modeling tools, designers have equipped with a serious capability to generate numerous 
spatial configurations and design alternatives which, in turn, would be analyzed within the same algorithmic setting, to guide better solutions. Since parametric modeling provides a large universe of possibilities for searching, analyzing and operating distinct design settings, it has gained a wide practical ground in the field of architectural and urban design. Nevertheless, despite its increasing use in design practice, its use in spatial analysis and research has fallen limited. Considering its current computational capacity, the existing research argues that parametric modeling can be employed in 'generative spatial research' that would ensure an efficient integration between analysis and design specifically on the issue of the urban heat island. Since urban geometry-based UHI studies are generally specialized either on measurement or on simulation techniques, the current analytical models do not suggest an integrated framework. Therefore, following the measures on specific urban areas, possible alternative formations are not generated in response to the given contextual constraints. Therefore, there exists a lack between morphological analysis and design from a context-sensitive perspective. To overcome such a shortcoming, the paper suggests an alternative model combining spatial analysis and formgeneration to mitigate UHI intensity.

This research aims to investigate the potentials of parametric modeling for analyzing morphological indicators of urban areas, and testing the alternative forms with regards to Urban Heat Island (UHI) effect, accordingly. By developing a parametric approach, following the calculation of UHI intensity in urban areas, a new (evidence-based) design control approach could be possible based on generating and testing alternative spatial patterns in the same operational framework. Eventually, opening up a methodical discussion on the problematic issue of urban heat island (UHI) is aimed.

To test the applicability of the proposed parametric model, an actual urban context in Ankara, Turkey is selected for the analysis and form generation. As one of the most rapidly transformed urban areas in the city, the selected neighborhood provides an opportunity to compare different morphologies while testing some hypothetical ones in the same planning context. That means alternative urban configurations will be tested based on the same development rights in the site. Then the possibility of mitigating UHI intensity in the given planning conditions will be discussed. With the model proposal, the effect of urban geometry on UHI development is to be revealed. The parametric model, in this framework, is aimed to perform as a design-support system 
informing urban design processes targeting for the mitigation of heat island intensity in the planned urban fabrics.

\section{URBAN HEAT ISLAND (UHI) AND URBAN GEOMETRY}

\section{Definition of Urban Heat Island}

Urban microclimate, which is formed by the complexity of morphological conditions of urban areas, basically influences temperature, air pressure, wind, humidity and precipitation of any regional climate (Yılmaz, 2013). Due to its negative impacts on thermal comfort, the dramatic differentiation in air temperature observed with higher values in the urban areas has been the subject of many spatial studies on the issue.

On the phenomenon of UHI, much of the progress in a robust understanding of heat island formation has been suggested by the researches of T.R. Oke. (1988) linked the magnitude of heat island effect to the energy balance of urban areas and improved the knowledge of urban microclimate. Energy balance, in this regard, is the main driver behind the ambient air and surface temperature differences in the context of the built and natural environment. Impermeable surface materials with low reflectance, the limited sky view due to the urban geometry, lack of vegetation and water surfaces in the built-up areas cause serious disparities in the heating and cooling capacity of the cities. As a result of the energy flux, when the thermal balance of the environment turns into a positive (heat storage), the heat of the environment increases and it conduces the development of the UHI effect (Oke, 1988; Santamouris et al., 2001; Erell et al., 2011). T.R. Oke has also conducted several studies about physical factors in the formation of UHI while correlating them to the issues of the urban population, weather conditions, thermal properties of surface materials and urban canyon geometry.

The magnitude of the heat island intensity may vary to the climate, geographic location and urban layout of the cities. Particularly, densification of the built-up areas, increased human activities due to population growth, anthropogenic heat release via energy consumption, the replacement of natural ground coverages by low reflective surfaces, demolition of moist surfaces or vegetation areas, and reduced wind speed within the streets cause temperature increase and make cities warmer than their natural surroundings. Such transformations in urban areas can create complex radiation exchange between the surfaces and the atmosphere, and thus contribute to a more intensive UHI effect (Oke et al., 1991; Santamouris et al., 2001; EPA, 2008). 
Following T.R. Oke's footsteps, several researchers have contributed to the field by providing an estimation of heat island intensity and mitigation strategies for that. As a result of all these studies, warmth characteristics of the surface areas and air temperatures in the built environment are examined. In urban areas, the mean air temperature is determined to be a minimum of 1 to $3^{\circ} \mathrm{C}$ warmer than suburban or rural areas, and it can reach up to 10 - 12 degrees (EPA 2008; Oke, 1973). Then the temperature difference between them is called as Urban Heat Island (UHI) intensity.

The development of larger heat island intensity, due to increase in density, and release of heat by basic human activities (i.e. transportation and industry), and greenhouse gas emissions in the urban areas cause serious climate change from local to the global scale. At least $1^{\circ} \mathrm{C}$ rise in air temperature of cities has a knock-on effect on global warming. The trend of warming has negative effects on human health, as well. High-temperature increases by extreme heat waves result in mortality risks in the cities (Santamouris et al., 2001; Wong and Chen, 2009). Therefore, mitigation of the UHI effect should be taken into consideration for the well-being of urban communities (Erell et al., 2011; Shahmohamadi et al., 2010).

\section{The Relationship between UHI and Urban Geometry}

Urban geometry has a certain effect on urban microclimate, and, specifically, on the development of the UHI intensity. During a day, incoming short-wave radiation is absorbed by the buildings, and stored as heat, internally. After the sunset, the urban surfaces that were warmed up during the day start to emit long-wave radiation and release heat during the night. However, urban geometry has a crucial role in the heat loss rate of the gained heat. When an urban geometry (i.e. building heights and street widths) involves deep canyons, the average sky view in the given fabric falls limited, thus radiation loss occurs lower than open spaces. In other words, as a result of restricted long-wave radiation and heat loss by the geometrical configuration of the urban fabric, residual heat contributes to the formation of heat island (Hammerle et al., 2011; Lopez et al., 2016; Oke, 1981; Unger, 2009). Therefore, these energy exchanges can be linked to the variables of urban canyons, and canyon geometry characterized by three main indicators: aspect ratio, sky view factor, and building orientation. These indicators have been demonstrated to have a significant impact on the UHI by several studies.

The aspect ratio of a canyon, or in other words, building height to street width $(\mathrm{H} / \mathrm{W})$ ratio has been found to be a significant factor 
contributing to UHI intensity (Oke, 1981; Bakarman and Chang, 2015; Takkanon, 2016). In general, an increase in the $\mathrm{H} / \mathrm{W}$ ratio as a result of created deep canyons in urban areas contributes to the development of the UHI effect. In heat island studies, threedimensional urban geometry data are transformed to the twodimensional sections to calculate the $\mathrm{H} / \mathrm{W}$ ratio. The role of the urban geometry indicators on the heat island effect is also controlled by the building orientation, or in other words, canyon axis orientation. The level of the solar access to the canyon, especially to the building facades, is highly determined by the orientation. In addition, street orientation has a significant impact on temperature reduction through airflow (Nunez and Oke, 1977; Lau et al., 2015). Even if these indicators have an enormous impact on the magnitude of the UHI effect, this study focuses on the three-dimensional representation of urban geometry and neglects some factors such as airflow patterns and insolation. Therefore, the Sky View Factor (SVF) calculation for the estimation of heat island intensity is determined as a measure.

Sky View Factor (SVF)

The Sky View Factor (SVF) is widely used as an important measure of urban geometry for the measurement of the UHI effect. The SVF is defined as the fraction of the visible sky. In other words, the SVF value represents the ratio of radiation from a given point to received from the entire hemispheric radiant (Johnson \& Watson, 1984). SVF basically conditions the ratio of emitted longwave radiation from urban surfaces to the atmosphere. Therefore, the fraction of the visibility of the sky from a point on the urban surfaces depending on the interception of the near located urban structures is indicated by a SVF value, which is within a range between the values, 0 and 1 . The SVF value of 1 means that the sky is unobstructed and completely visible, whereas if it gets the value of 0 , that means the sky is completely blocked from the ground level. When the SVF value decreases due to high-rise buildings and narrow streets, in addition to the multiple reflections, long-wave radiation loss is restricted, heat is trapped, and thus heat island effect is increased in urban canyons (Hammerle et al., 2011; Unger, 2009). (see: Figure 1)

Figure 1. The relation between SVF values and emitted long-wave radiation

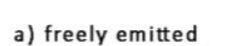

long-wave radiation

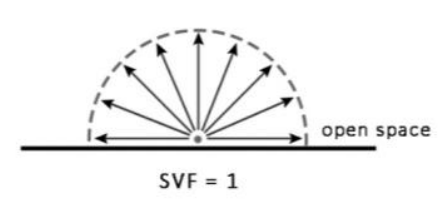

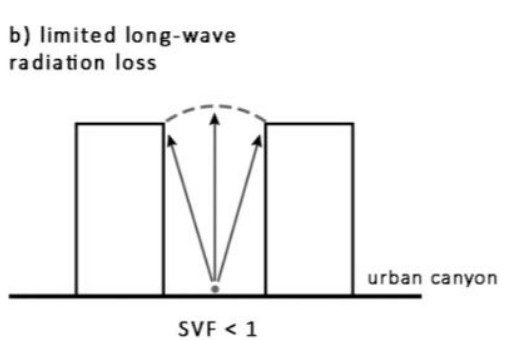


The basic calculation method of the SVF is based on the projection of each building surfaces which are seen from the point as an obstruction to a hypothetically set hemisphere (sky vault) from a specific point in an urban area. This illustrates the interrupted portion of the sky seen from a certain point of the observer. The ratio of the remaining part is considered as the SVF value, and it is formulated by subtracting the sum of all view factor values of building surfaces from 1 (Unger, 2009). (see: Figure 2)
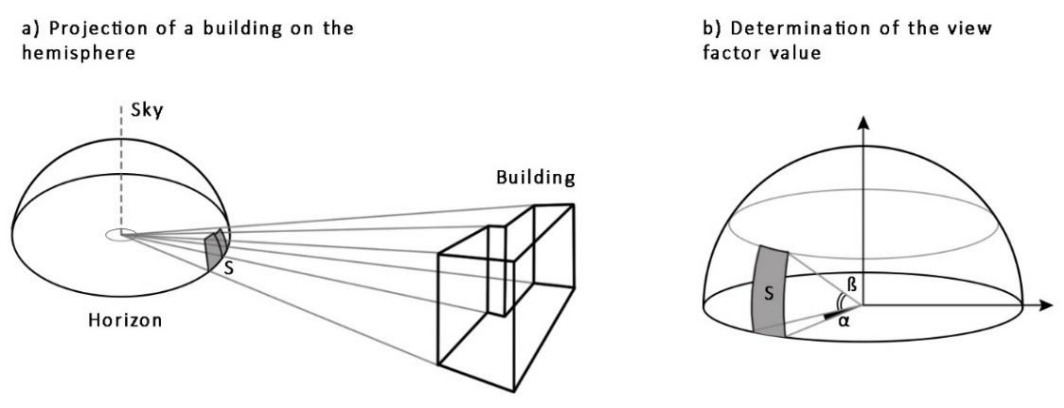

Many studies have proved a strong correlation between the SVF value and the UHI effect in urban areas. Comparisons of measured air temperatures at different urban sites and calculated SVF values show that urban geometry had a significant impact on the distribution of the average air temperature (Svenson, 2004). To demonstrate the correlation between them and to calculate UHI intensity $(\Delta T u-(\max ))$, Oke (1987) formulated a new equation using the SVF ( $\psi s k y)$ as a measure:

$$
\Delta T_{u-r(\max )}=15.27-13.88 \psi_{\text {sky }}
$$

According to the equation, the measured SVF value is be multiplied by 13.88 , then the obtained value is be subtracted from 15.27. For this mathematical operation, Oke (1981) made a series of SVF measurements in the central urban areas of Australian, European and North American cities where urban heat island intensity data was available. Comparing the measurement results, he came up with a strong inverse correlation between maximum heat island intensity and the sky view factor observed. The resulting relationship provided the equation of linear regression with $r^{2}=0.88$ and a standard error of the estimate of $\Delta T_{u-r(\max )}$ of $\pm 0.92^{\circ} \mathrm{C}$.

\section{METHOD OF THE RESEARCH: A MODEL PROPOSAL}

The methodical approach of this study stands on the systemic combination of analysis and simulation processes. To mitigate UHI intensity in urban areas, the proposed model provides the combination of the SVF calculation by analyzing the morphology
Figure 2. Schematic depiction of the SVF calculation (Unger, 2009) 
of urban fabric, and form-generation through maximizing the obtained SVF values at the same algorithmic setting. Then, in the first stage, the layout of the selected area is to be analyzed to calculate the SVF value and UHI intensity on the base of the formulation of Oke's (1987). In the second phase, the alternative urban compositions will be simulated in the search for minimizing heat island intensity through maximum levels of the SVF. By the simulation based on the parametric modeling, a set of alternative form typologies ensuring maximized SVF values are aimed to be provided. For the parametric modeling, Grasshopper $®$, a graphical algorithm editor integrated with Rhino's 3-D modeling tools has been used.

\section{Algorithmic Definitions of the Morphological Indicators of UHI}

To analyze the effect of urban geometry on heat island intensity regarding SVF value while reproducing the test case during the generation of alternative fabrics, parametrically, the algorithmic framework of the model has to be defined. To that end, the key morphological components as the major inputs of the algorithmic setting are specified along with the related parameters. In this context, the block, the plot, and the building are considered as the elements of urban form that would be parameterized to define the main morphological indicators of UHI.

Figure 3. Schematic illustration of the effect of major parameters on the visibility of the sky

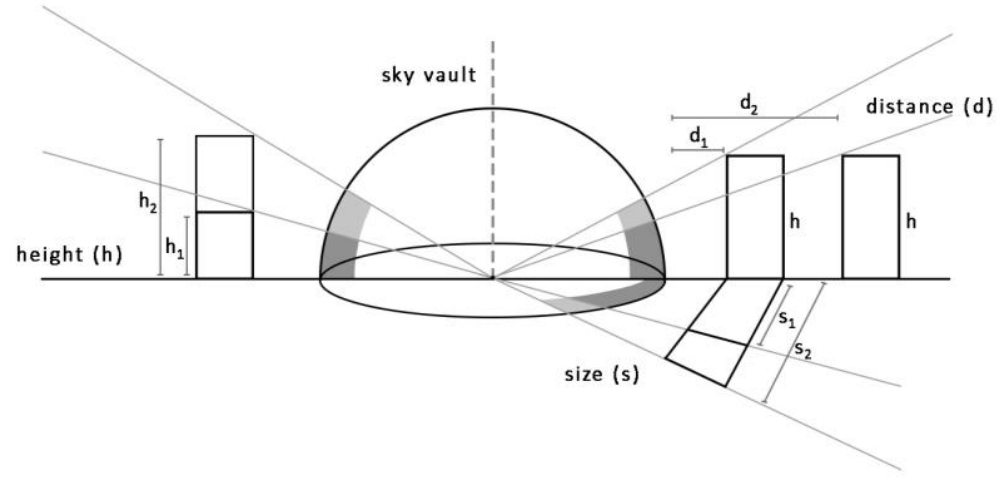

Previous studies on the issue show that main morphological factors on the relationship between SVF and heat island intensity are as follows:

- the height of the buildings,

- the distance between the buildings,

- the distance between the measurement point and buildings,

- $\quad$ and the size of the buildings.

As shown in Figure 3, the variation in the main parameters of urban geometry (height, distance, and size) induces an obstruction of the sky view in different sizes. When the average 
height of the building increases in a certain direction $(h 2>h 1)$, the obstructed field in the given direction also increases. However, an increase in the distance between the test point and the buildings $(d 2>d 1)$ results in a decrease in the obstruction of the visibility within the condition of the same building heights. Moreover, the more the building coverage -with the same floor area ratio (FAR), the higher the value of the SVF is obtained.

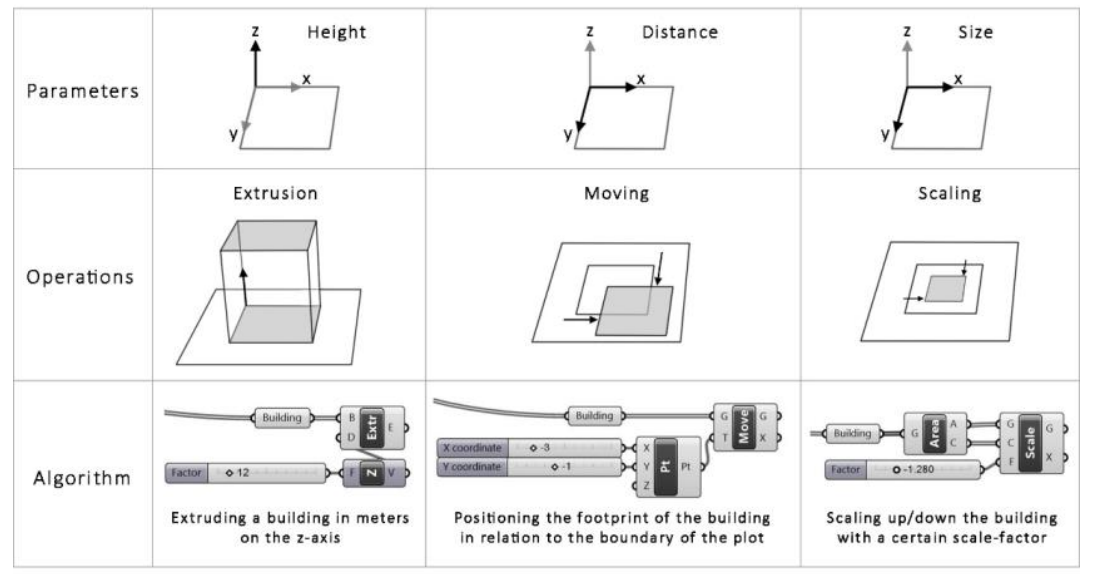

To generate alternative fabrics for the test case, the basic morphological operations have to be defined, as well. In this context, extrusion, moving, and scaling are specified as the main parametric operations involved in the generative algorithm. (see: Figure 4)

In the search for alternative configurations to mitigate heat island intensity effect in the built fabric, the key morphological indicators are determined regarding the legislative framework of the Turkish spatial planning system that regulates the development of the urban form. In the development plans in Turkey, building coverage, floor area ratio (FAR) and a maximum height of the buildings (Hmax) within the given planning context are the three basic form indicators involved in the development plans. In the current study, coverage and FAR are determined as the basic indicators controlling the simulation process in the generation of hypothetical alternative urban fabrics.

\section{Algorithmic Setting for the Analysis}

To calculate SVF value in urban areas, a new technique that is based on the algorithmic calculation of geometric features is suggested. Geometric components of urban areas were quantified by a special algorithm based on the specified viewpoints computing the SVF values through the hemispheric projection of the buildings. With the use of the algorithmic model, the distribution of SVF values in an urban fabric, and the magnitude of UHI intensities at those areas can be calculated and compared. This proposed model, in this framework, calculates the SVF values
Figure 4. Schematic depiction of algorithmic attributions 
in three steps, positioning (the measurement points and the fields of analysis), projection (of the hypothetical hemisphere) and extraction (of the obstructed fields).

Figure 5. Phase 1: The consecutive steps to position the measurement point and the fields of analysis

Figure 6. Phase 2: Projection of the buildings on the hemisphere

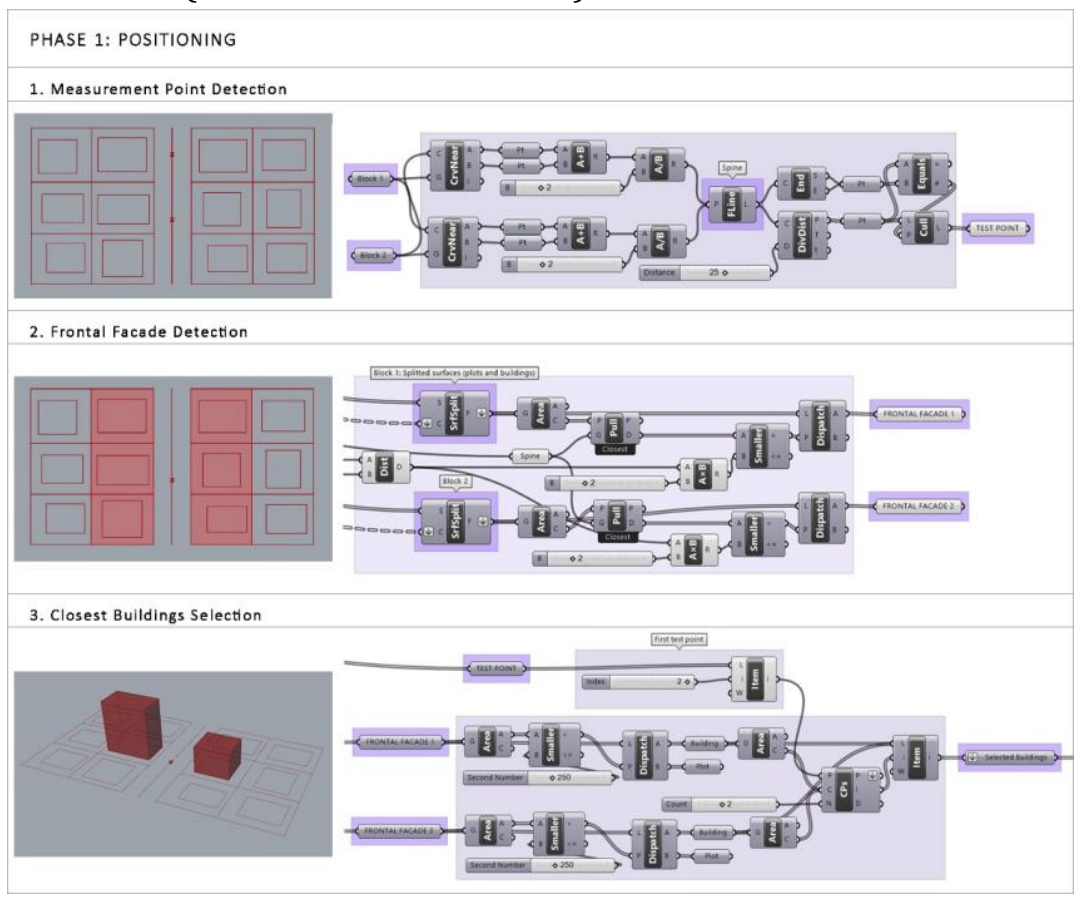

The first phase of positioning is run by the decision-making algorithm for selecting the measurement points, the plots and the buildings that are visible from the point where the SVF calculation is to be made, accordingly. Then in the first phase, the measurement point is specified, the plots facing the specified point are classified, and the closest buildings to the point in the given segment are selected, respectively. (see: Figure 5).

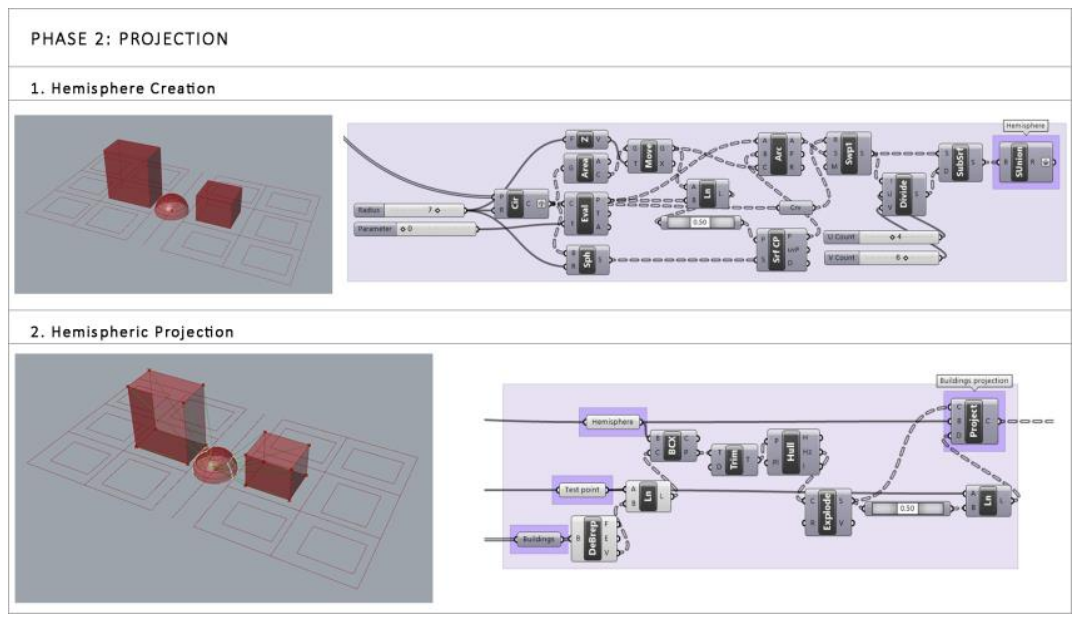

In the second phase called projection, first, a hypothetical hemisphere is generated at the center of the urban canyon. To cover the street section, completely, the radius of the hemisphere is set as half of the street width. Then, with the use of buildings, 
the test point, and the hemisphere, the projection lines are generated from the measurement point to the edge of buildings. As a result of that operation, the obstructed area on the sky vault by buildings is detected. (see: Figure 6 )

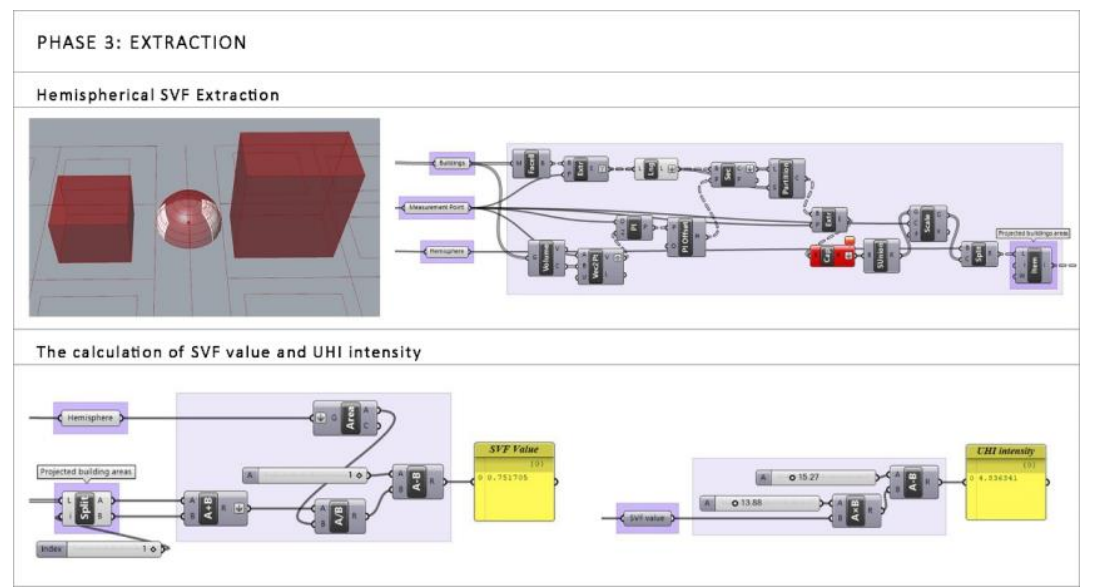

After the projection process, in the third phase of setting the analytical algorithm, extraction is made to calculate the SVF value and UHI intensity. The SVF value was computed by the subtraction of the ratio of the total projected buildings area to the surface area of the hemisphere from 1 . Then, the UHI intensity was calculated with the use of Oke's (1987) formulation, accordingly. (see: Figure 7)

\section{Algorithmic Setting for the Simulation}

Proposing a parametric model to simulate the alternative form compositions ensuring higher SVF values for the mitigation of UHI intensity, requires a generative algorithmic setting. For this purpose, Galapagos $®$, an evolutionary computing tool operating within the parametric model to test the input parameters within the automatic generation of alternative geometries is used. The algorithmic framework is designed to evaluate the given parameters (i.e. height, distance, size) via Galapagos ${ }^{\circledR}$. Then the simulation is run for testing the impact of any change in the value of the parameters on the visibility of the sky represented by SVF. Therefore, a set of alternative configurations are to be obtained following the changes in the parameters of the urban geometry. In this context, the morphological indicators of coverage and floor area ratio (FAR) are introduced as a constraining factor characterizing the simulation of alternative urban tissues by the generative algorithm.
Figure 7. Phase 3: Extraction of the SVF from the hemispherical projection model 
Figure 8. The SVF simulation based on the parameter, building height

Figure 9. The SVF simulation based on the parameter, distance

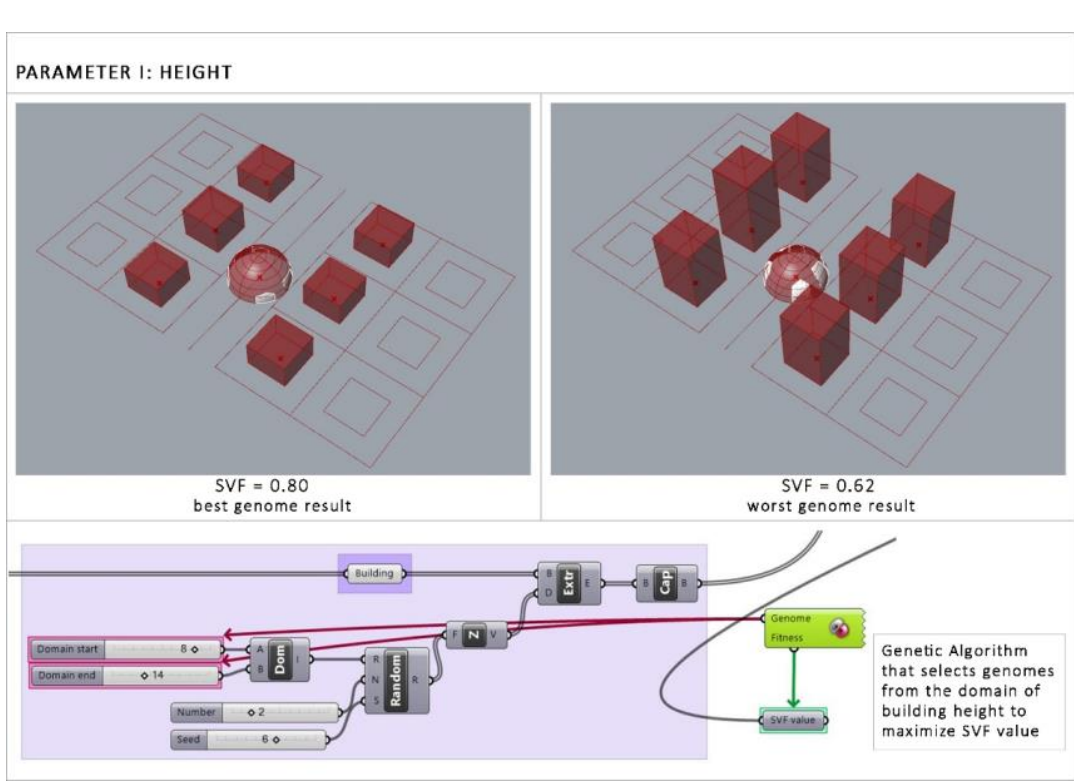

The involvement of the morphological parameters in the simulation is set separately from to reveal their specific influence on the SVF. For instance, in consideration of the changing parameter of height, Galapagos ${ }^{\circledR}$ tends to simulate the optimum form-compositions maximizing the SVF value within the given range of building heights.

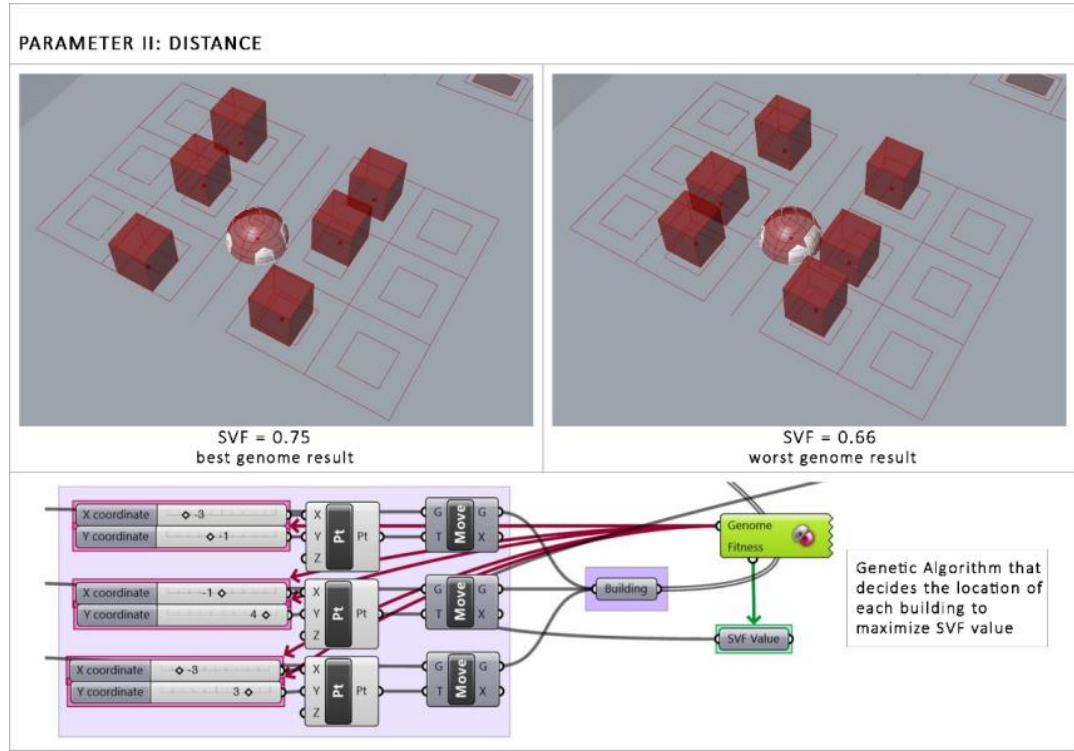

As another key parameter for the simulation, the distance between the measurement point and the buildings is varied via the movements of the buildings on $\mathrm{x}$ and $\mathrm{y}$ coordinates. The alteration in each building location results in different SVF values, which is optimized by a series of iterations via Galapagos ${ }^{\circledR}$. The simulation results show that even small differences in the distance of buildings to the test point cause significant changes in the SVF value. (see: Figure 9) 


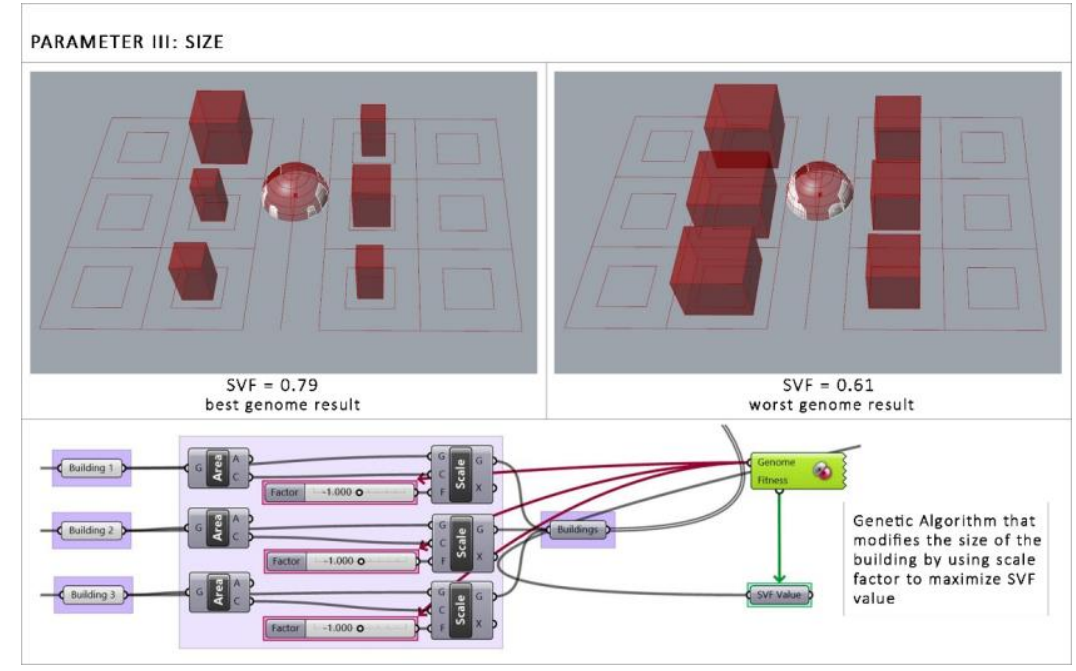

Changes in the building coverage area conditioned by the parameter of size are also simulated for getting a range of SV results. Since the height of the buildings within a given area is fixated in a certain value, any increase in the coverage of the buildings directly affects their volume, which, in turn, would change the average SVF value in the given fabric. The simulation run by the scaling tool that controls the size of the building by a specific scale-factor constrained by coverage of the building. (see: Figure 10)

\section{APPLICATION OF THE MODEL IN THE ACTUAL URBAN CONTEXT}

For the demonstration of the proposed parametric model that aims for the integration of parametric modeling with design control in planning, this model is applied in an actual urban context. For this purpose, an urban transformation area has been selected to make a comparative analysis of the fabric before and after the redevelopment process. Then the alternative urban fabrics are to be generated with the same (re)development codes provided by the new plan of the site. In this way, the effects of urban geometry on the intensity of UHI would be tested against the actual and hypothetical morphologies. Sharing the same consideration of adapting SVF into actual design and planning processes, the following application of computational modelling could be considered the successor of the early typomorphological analysis made by Canan (2017) in the case of Konya, Turkey.

\section{Case Study Area}

The selected site for the application of the model locates in one of the rapidly transforming districts in Ankara. By the mid-2000s, the land use pattern in the area got highly diverse in a fragmented manner. At that period, Ankara Metropolitan Municipality enacted
Figure 10. The SVF simulation based on the parameter, building size 
a new master plan envisaging a planned renewal in the form of redevelopment within the area. From that year on, a significant spatial transformation has taken place in the area. (see: Figure 11)

Figure 11. Satellite images of the case study area before and after the transformation (above), and figureground map of the area with that of the new fabric after the redevelopment (below) -dated in 2005 and 2018 respectively
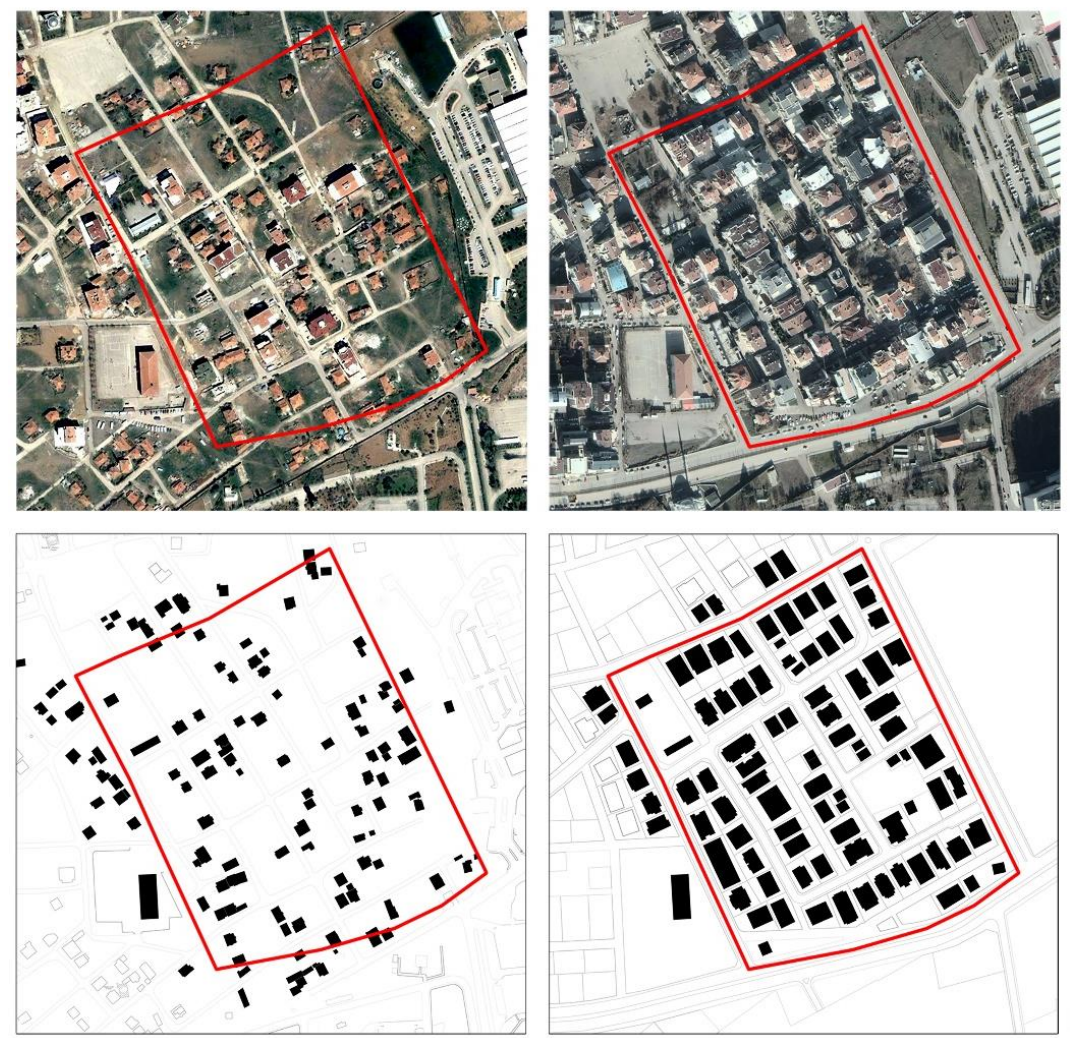

The case study area represents a very common example of the typical spatial pattern redeveloped upon the existing pattern of the informal urban fabric. Keeping the layout of the old tissue intact, the plan transforms the old fabric by a radical increase in development rights through coverage, FAR and maximum building height. To have a consistent typological framework, the area of the model application has been specified as a representative section that was comprised of the homogenous collective fabric.

\section{Case Study Analysis: SVF Calculation}

In the first stage of the model application, the points of the SVF calculation are generated by the algorithm. To ensure a homogenous measuring point distribution, the distance between each measurement point is specified according to the length of the street. Then, the distance between the measurement point and buildings' centroids are defined for the selection of the buildings to be projected on the hypothetic hemisphere. (see: Figure 12) 


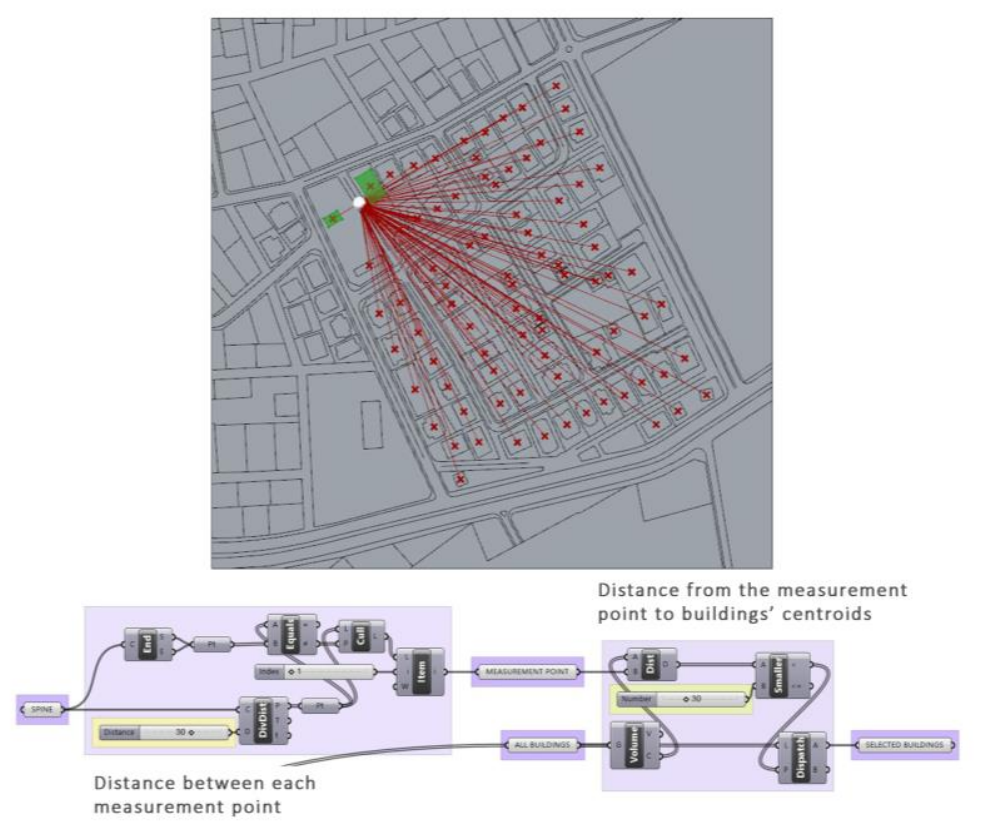

By multiplying this sub-algorithm, the selection of all buildings to be used for SVF calculation is provided. The positioning of the points and the hemispheres attached accordingly are aimed to configure a homogenous distribution throughout the area. (see: Figure 13)

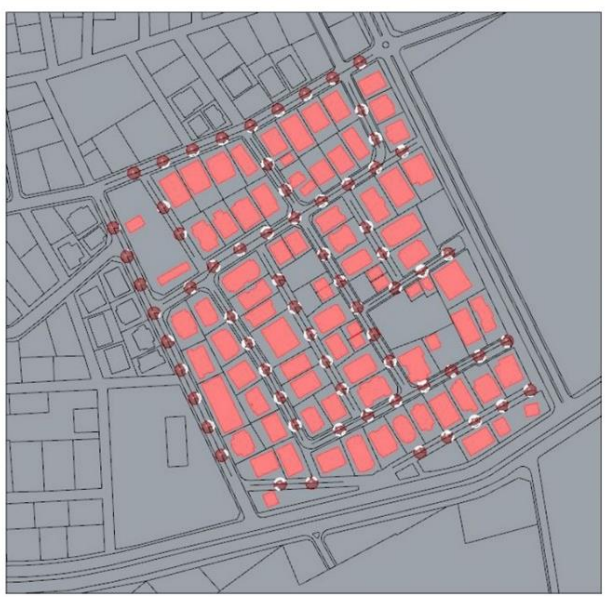

In the SVF calculation, to compare the current state of the art in the study area with the condition before the transformation took place, the analysis has been applied to the two fabrics. With the analysis, it is found that the informal housing area with 1-2 storey buildings has a higher mean SVF value (0.91) than that of the planned fabric $(0.75)$. Then the heat island intensity is calculated lower $\left(2.48^{\circ} \mathrm{C}\right)$ in the loose fabric of the transformed area than that in the redeveloped new fabric $\left(4.75^{\circ} \mathrm{C}\right)$. Higher building density introduced by the (re)development plan ends up with a serious increase in the magnitude of the UHI effect. This actually provides the initial demonstration of the actual effect of urban
Figure 13. Application of the algorithmic set of analysis on the area

Figure 12. Algorithmic setting of the building selection for measurement points 
geometry on the condition of heat island intensity in the built fabrics.

Figure 14. Comparison of measurement results (SVF and UHI intensity)

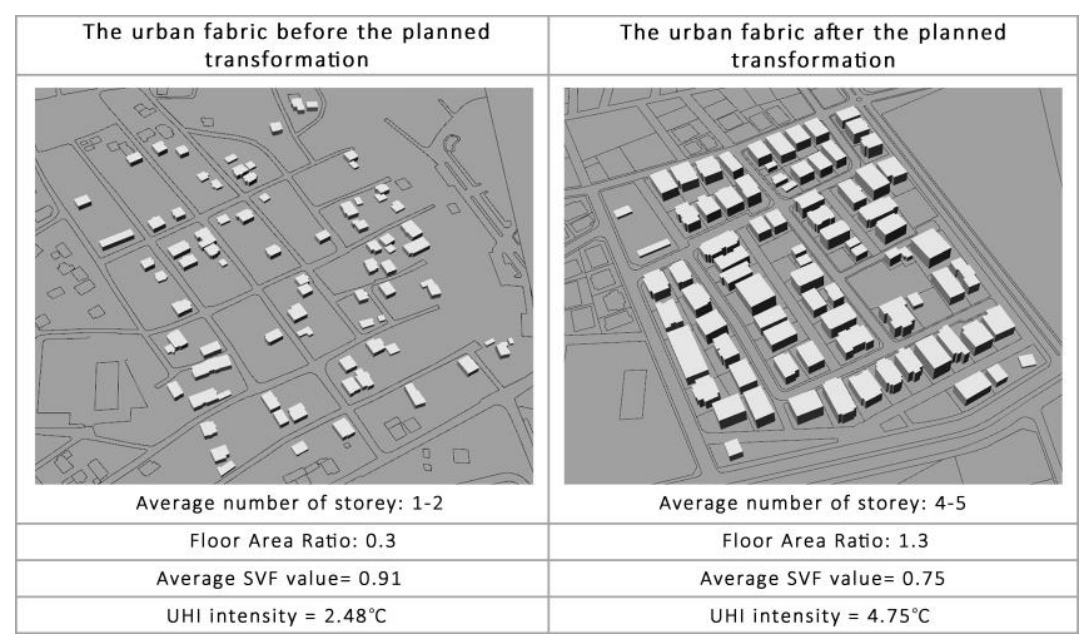

Testing the Hypothetical: Generation of Alternative Fabrics

In the second stage of the model application, alternative compositions are simulated on the same layout to reveal more about the actual effect of urban geometry on heat island intensity on a hypothetical basis. In this context, the floor area ratio (1.3), the actual development right which is specified by the development plan of the area is taken as the basic constraining factor of the form-variation in the simulation process. That ensures the total building volume remaining constant in each alternative layouts by the simulation. This would also enable the authors to compare the hypothetical models with the actual conditions before and after transformation. By the generative phase of the proposed model, the relative thermal performance of the formal variations within the same typology is aimed to discuss. That means, rather than addressing a specific typology as the so-called 'good urban form', the intrinsic effect of subtle morphological variations on the heat island intensity is aimed to reveal by the analysis of the simulated models. Then, the behaviors of the form-variations within the specified typologies, point-block, row housing, and perimeter block will be discussed, respectively, as follows.

In this framework, the first variation is searched on the pointblock typology. Within the same building density, the change in building heights that inevitably manipulates the coverage of the buildings, seemingly, results in variations in the mean SVF values, and thus influences the magnitude of heat island intensity. Accordingly, for instance, the 3-storey point blocks with the average building footprint of $380 \mathrm{~m}^{2}$ tend to generate $4.78^{\circ} \mathrm{C}$ heat island intensity through the whole fabric. When the building height increases from 9 meters to 15 meters, the UHI intensity has reached up to $4.87^{\circ} \mathrm{C}$. Whereas, when the average building height 
increases to 30 meters, we can see a significant decrease in UHI intensity, as well. (see: Figure 15)

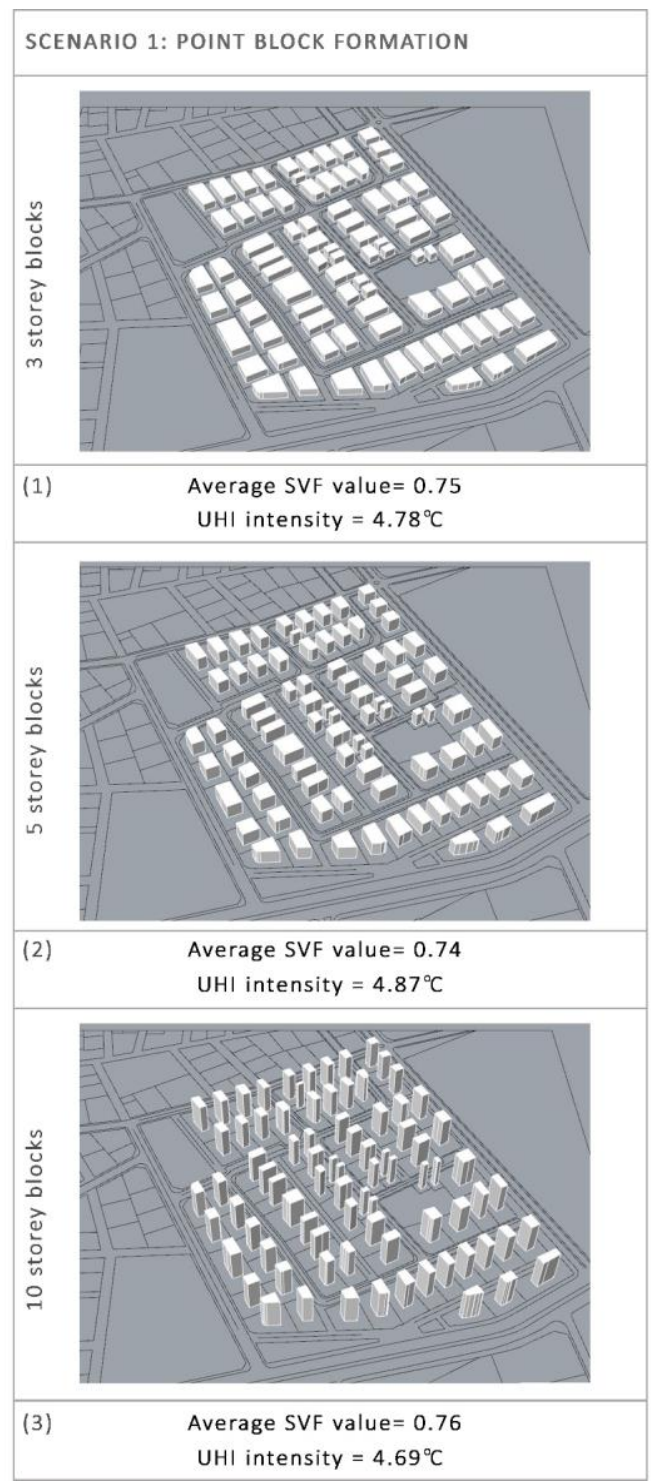

Table 1. Parametric variations of the simulated morphologies and their relative performances on the UHI intensity (point-block typology)

\begin{tabular}{|c|c|c|c|c|c|c|}
\hline Variations & FAR & Coverage & $\begin{array}{c}\text { Building } \\
\text { Height } \\
\mathbf{( m )}\end{array}$ & $\begin{array}{c}\text { Average } \\
\text { Footprint } \\
\text { Area } \mathbf{( m}^{\mathbf{2}} \mathbf{\text { }}\end{array}$ & $\begin{array}{c}\text { Average } \\
\text { SVF } \\
\text { Value }\end{array}$ & $\begin{array}{c}\text { UHI } \\
\text { Intensity }\end{array}$ \\
\hline $\mathbf{1}$ & 1.3 & 0.42 & 9 & 379 & 0.7553 & $4.78^{\circ} \mathrm{C}$ \\
\hline $\mathbf{2}$ & 1.3 & 0.25 & 15 & 224 & 0.7492 & $4.87^{\circ} \mathrm{C}$ \\
\hline $\mathbf{3}$ & 1.3 & 0.12 & 30 & 110 & 0.7617 & $4.69^{\circ} \mathrm{C}$ \\
\hline
\end{tabular}

This implies the subtle relationship between the parameters of building height and ground coverage on UHI intensity. The simulation results show that increased building sizes on the vertical plane have a greater effect on the rise in the air
Figure 15. Compositional variations of the point-block typology, and the average SVF values of the fabrics generating a certain level of UHI intensity 
temperature than the horizontal one. In other words, the UHI effect tends to increase as the building height increases. Though it seems that low-rise buildings have an advantage in heat loss up to a certain height, the increased level of porosity generated by the decreasing footprints (along with the increase in building heights within the same density) leads to a decrease in heat island intensity (see Table 1). Increased open spaces between buildings providing a high level of visibility of the sky help to reduce ambient air temperature by increasing the emittance of long-wave radiation. Then an increase in the building height can be interpreted as an influential factor, more open spaces between buildings (via increased setbacks) may gain priority for the mitigation of the heat island intensity.

In the second typological variation, three forms of row-housing fabric are simulated along with their corresponding average SVF values and UHI intensity. (see: Figure 16)

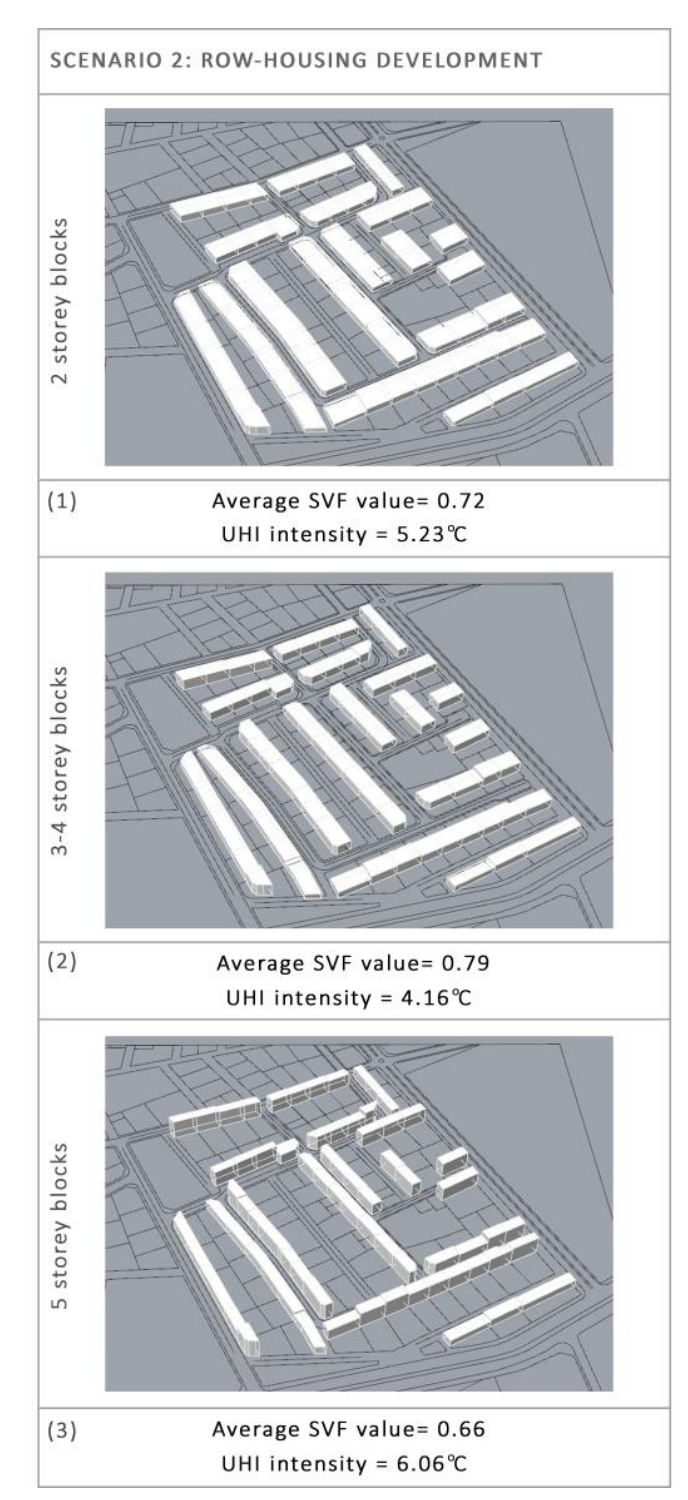

Figure 16. Compositional variations of the row housing typology, and the average SVF values of the fabrics generating a certain level of UHI intensity 
Design for Mitigating Urban Heat Island: Proposal of a Parametric Model

Table 2. Parametric variations of the simulated morphologies and their relative performances on the UHI intensity (row-housing typology)

\begin{tabular}{|c|c|c|c|c|c|c|}
\hline Variations & FAR & Coverage & $\begin{array}{c}\text { Building } \\
\text { Height } \\
\mathbf{( m )}\end{array}$ & $\begin{array}{c}\text { Average } \\
\text { Footprint } \\
\text { Area } \mathbf{( m}^{\mathbf{2}} \mathbf{\text { Average }}\end{array}$ & $\begin{array}{c}\text { UHI } \\
\text { SVF } \\
\text { Value } \\
\text { Intensity }\end{array}$ & \\
\hline $\mathbf{1}$ & 1.3 & 0.55 & 6 & 571 & 0.7229 & $5.23^{\circ} \mathrm{C}$ \\
\hline $\mathbf{2}$ & 1.3 & 0.40 & $9-12$ & 417 & 0.7997 & $4.16^{\circ} \mathrm{C}$ \\
\hline $\mathbf{3}$ & 1.3 & 0.27 & 15 & 276 & 0.6629 & $6.06{ }^{\circ} \mathrm{C}$ \\
\hline
\end{tabular}

Simulation results show that an increase in the building height causes an increase in the air temperature. To illustrate, the highest UHI intensity $\left(6.06^{\circ} \mathrm{C}\right)$ with the lowest mean SVF value $(0.66)$ is calculated for the fabric comprised of the highest building configuration. (see: Table 2) Since the row-housing fabric consists of narrow canyons with the long facade facing streets, building height becomes one of the most important factors for this formation. However, the simulation results also show that the UHI effect can be reduced by modifying setbacks to increase the open spaces between buildings, and to promote heat loss within those spaces. For instance, when the front yard setbacks are set to by putting a larger distance between the facing facades of the rowhouses, the heat island intensity would be manipulated to $4.16^{\circ} \mathrm{C}$. This basically displays the critical relationship between the building height and the setbacks in mitigation of UHI intensity.

Finally, the third simulation enables to illustrate the relative performance of the different urban compositions within the typology of the perimeter block. In this framework, without changing the setback distances of the outer peripheries of the blocks, giving different values to coverage ends up with observed differences in height while still keeping FAR the same. This eventually generated different behaviors of the fabric with regards to the development of the UHI effect. (see: Figure 17) 
Figure 17. Compositional variations of the perimeter block typology, and the average SVF values of the fabrics generating a certain level of UHI intensity

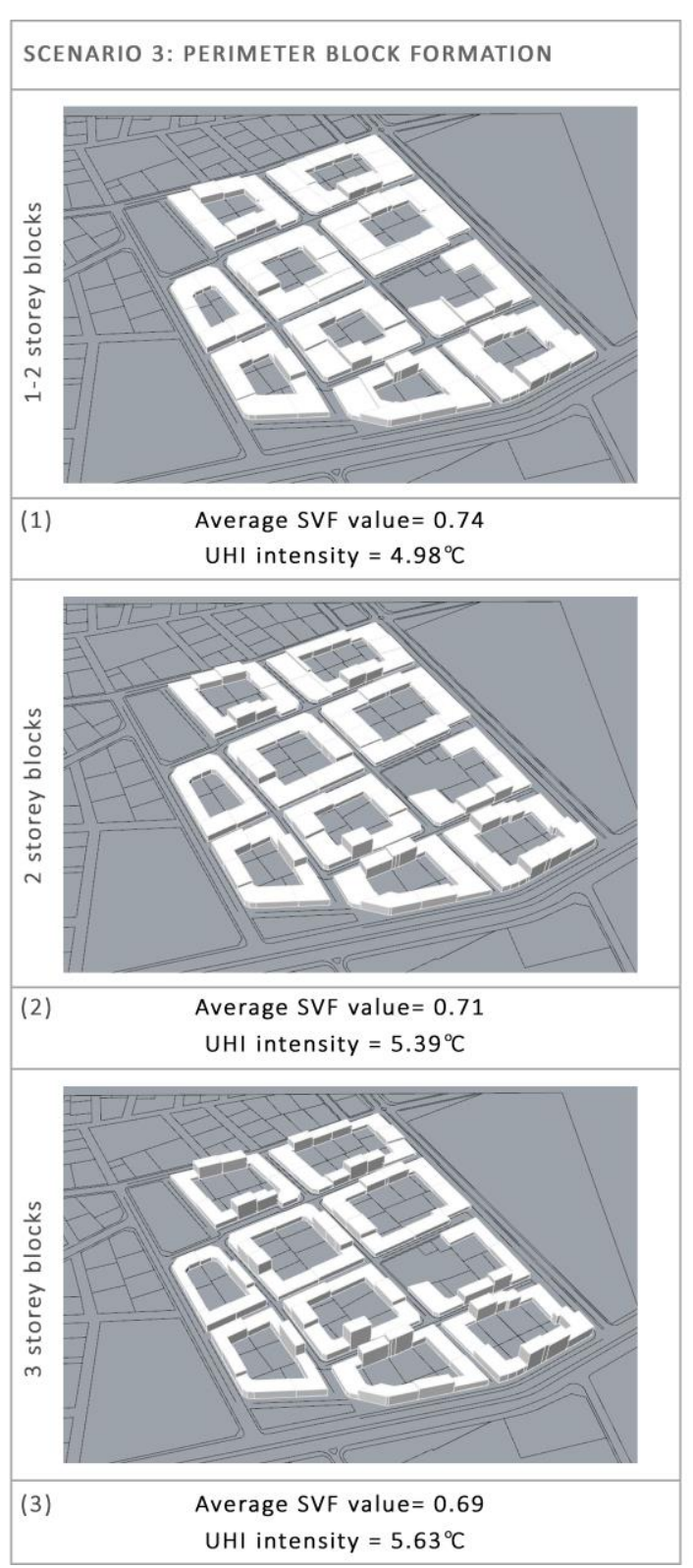

Table 3. Parametric variations of the simulated morphologies and their relative performances on the UHI intensity (perimeter block typology)

\begin{tabular}{|c|c|c|c|c|c|c|}
\hline Variations & FAR & Coverage & $\begin{array}{c}\text { Building } \\
\text { Height } \\
\text { (m) }\end{array}$ & $\begin{array}{c}\text { Average } \\
\text { Footprint } \\
\text { Area (m } \mathbf{( m}^{\mathbf{2}}\end{array}$ & $\begin{array}{c}\text { Average } \\
\text { SVF } \\
\text { Value }\end{array}$ & $\begin{array}{c}\text { UHI } \\
\text { Intensity }\end{array}$ \\
\hline $\mathbf{1}$ & 1.3 & 0.79 & $3-6$ & 770 & 0.7408 & $4.98^{\circ} \mathrm{C}$ \\
\hline $\mathbf{2}$ & 1.3 & 0.68 & 6 & 657 & 0.7116 & $5.39^{\circ} \mathrm{C}$ \\
\hline $\mathbf{3}$ & 1.3 & 0.54 & 9 & 524 & 0.6941 & $5.63^{\circ} \mathrm{C}$ \\
\hline
\end{tabular}

Parametric variations in the given typology shows that, the highest UHI intensity $\left(5.63^{\circ} \mathrm{C}\right)$ with the lowest SVF value $(0.6941)$ along the streets was observed in the third alternative which comprises of the highest average building height, while the fabric with the lowest average level of building height (1-2 storey) 
reveals the maximum performance on UHI effect. Nevertheless, it should also be noted that when the building height decreases, the building blocks tend to get more compact in form, thus, that might cause a rise in the ambient temperature in the inner courtyards of those areas.

\section{CONCLUSION}

This paper discusses the potentiality of parametric modeling in the analysis of the actual urban fabrics in terms of their intrinsic performance on urban heat island (UHI), as well as the possibility to integrate such an analytical framework into the generative capacity of parametric design. In this way, a combinatoric model would be suggested to test both the old and existing fabrics and the new ones simulated based on certain morphological parameters. Suggesting a performative tool for analysis and design, the model is believed to provide urban designers and planners with a proactive perspective on the issue of urban climate with a particular focus on UHI.

Even though evaluations on the form variations are limited to generalize the future design solutions, the research would contribute to the development of an operational basis of evidencebased urban design regarding urban heat island intensity as one of the crucial climatic problems for urban areas. Since it is based on the processes of 'learning by doing' by which multiple design solutions are simultaneously generated and tested against certain performance criteria (Sailer et al., 2008), the evidence-based design pursued by the computational methods in is potentially enhancing the already emerging performative design approach in urbanism. Such an approach would also ensure systemic research in the formulation of responsive strategies and tactics to achieve better design solutions (Karimi and Vaughan, 2014). In this regard, the proposed parametric model can be considered as a kind of 'decision support system' (DSS) that informs the designing of collective urban from the specific perspective of the UHI effect in urbanism.

It is important to note that since the research mainly aims to design an operational model for climate-responsive urban design, the model application does not tend to come up with a normative framework idealizing certain typologies as the optimum and universal design solution in the name of 'good urban form' with regards to the issue of UHI. Instead, the relative performances of different urban geometries within the same typology are aimed to discuss. This basically enabled us to focus the discussion on the 
parametric variation of urban form and its climatic performance within the specified constraints.

At this point, one should address the certain limitations of the model proposal of the research. First of all, the analytical setting of the model is constructed on the calculation of SVF to reveal the UHI effect in the fabric. The main intention behind such specification is to improve the already established perspective in the existing literature on the issue. Nevertheless, it should be noted that an improved version of analysis considering the internal spaces of urban blocks (in addition to those on the streets) would suggest a more comprehensive analytical framework for the mitigation of UHI in urban fabrics. Moreover, future studies taking the other factors such as orientation pattern, wind behavior of the context and vegetation in consideration of the analysis would potentially provide robust modeling techniques for better practice in climate-sensitive urban design and morphology.

\section{REFERENCES}

Bakarman, M. A., \& Chang, J. D. (2015). The influence of height/width ratio on urban heat island in hot-arid climates. Procedia Engineering, 118, 101-108.

Canan F. (2017). Kent geometrisine bağlı olarak kentsel isı adası etkisinin belirlenmesi: Konya örneği. Çukurova Üniversitesi Mühendislik-Mimarlık Fakültesi Dergisi, 32(3), 69-80.Doi: 10.21605/cukurovaumm

Erell, E., Pearlmutter, D. \& Williamson, T. (2011). Urban microclimate: Designing the spaces between buildings. Earthscan: London.

Hammerle, M., Gál, T. M., Unger, J. \& Matzarakis, A. (2011). Introducing a script for calculating the sky view factor used for urban climate investigations. Acta Climatologica et Chorologica, 44, 83-92.

Johnson, G. T. \& Watson, I. D. (1984). The determination of viewfactors in urban canyons. Journal of Applied Meteorology and Climatology, 23, 329-335.

Karimi, K. \& Vaughan, L. (2014). An evidence-based approach to designing new cities: The English New Towns revisited, Chapter 22 in explorations in urban design: An urban design research primer, 261-276.

Lau, K. K. L., Thorsson, S., Lindberg, F. \& Holmer, B. (2015). Street geometry design and its effect on mean radiant temperature: A parametric study based on numerical modelling. 9th International Conference on Urban Climate 
jointly with 12th Symposium on the Urban Environment, Toulouse.

Lopez, C. S. P., Sala, M., Tagliabue, L. C., Frontini, F. \& Bouziri, S. (2016). Solar radiation and daylighting assessment using the Sky-View Factor (SVF) analysis as method to evaluate urban planning densification policies impacts. Energy Procedia, 91, 989-996.

Nunez, M. \& Oke, T. R. (1977). The energy balance of an urban canyon. Journal of Applied Meteorology, 16, 11-19.

Oke, T. R. (1973). City size and the urban heat island. Atmospheric Environment, 7, 769-779.

Oke, T.R. (1981). Canyon geometry and the nocturnal urban heat island: Comparison of scale model and field observations. Journal of Climatology, 1, 237-254.

Oke, T. R. (1987). Boundary layer climates, 2nd edition. Routledge: London.

Oke, T. R. (1988). The urban energy balance. Progress in Physical Geography, 12, 471-508.

Oke, T. R., Johnson, G. T., Steyn, D. G. \& Watson, I. D. (1991). Simulation of surface urban heat islands under ideal conditions at night: Diagnosis and causation. Boundary Layer Meteorology, 56, 339-358.

Sailer, K., Budgen, A., Losdale, N., Turner, A. \& Penn, A. (2008). Evidence-based design: Theoretical and practical reflections of an emerging approach in office architecture. In: The 4th Design Research Society Conference, Sheffield, UK.

Santamouris, M., Asimakopoulos, D. N., Assimakopoulos, V. D., Chrisomallidou, N., Klitsikas, N., Mangold, D., et al. (2001). Energy and climate in the urban built environment. James \& James: London.

Shahmohamadi, P., Che-Ani, A. I., Ramly, A., Maulud, K. N. A. \& Mohd-Nor, M. F. I. (2010). Reducing urban heat island effects: A systematic review to achieve energy consumption balance. International Journal of Physical Sciences, 5, 626-636.

Svensson, M. (2004). Sky view factor analysis - implications for urban air temperature differences. Meteorology Applications, 11, 201-211.

Takkanon, P. (2016). A study of height to width ratios and urban heat island intensity of Bangkok. 4th International Conference on Countermeasures to Urban Heat Island, Singapore.

U.S. Environmental Protection Agency (EPA). (2008). Urban heat island basics. In: Reducing urban heat islands: Compendium of strategies. Draft. https://www.epa.gov /heat-islands/heat-island-compendium. 
Unger, J. (2009). Connection between urban heat island and sky view factor approximated by a software tool on a 3D urban database. International Journal of Environment and Pollution, 363, 1-3.

Wong N. H. \& Chen, Y. (2009). Tropical urban heat islands: Climate, buildings and greenery. Taylor \& Francis: New York.

Yılmaz, E. (2013). Ankara şehrinde ısı adası oluşumu. Unpublished doctoral dissertation, Graduate School of Social Sciences, Ankara University, Ankara.

\section{Resume}

Begüm Sakar is currently continuing her PhD study at METU Faculty of Architecture, Department of City and Regional Planning, Ankara, Turkey. She completed her masters' degree in the Graduate Program of Urban Design at Middle East Technical University in 2018. Since 2016, she has been working as a research assistant in the same department at METU. In 2013, her graduation project was awarded by the UCTEA Chamber of City Planners within the Planning Students Graduation Project Competition. Her research interests are climate responsive urban design, bioclimatic comfort in urban spaces, and spatial research by Space Syntax.

Having completed his doctoral degree on urbanism at TU Delft, the Netherlands in 2013, Olgu Çalışkan has been lecturing at METU Faculty of Architecture, Department of City and Regional Planning and coordinating the Master of Urban Design Studio as assistant professor. His publications involve the book, Urban Compactness (VDM, 2009), guest editorial for the journal of Built Environment (2011), and several articles, including those in the Journal of Urban Design(2010/15), and Journal of Architectural and Planning Research (2011), Urban Design International (2012) and Urban Morphology (2017). His main research interests are physical planning and design, urban morphology, urban design theory and methodology, and visualisation in urbanism. Within the design team composed by Özer|Ürger Architects and Șemsettin Tugay, Olgu Çalışkan received the first price at Antalya Konyaalt Waterfront Design Competition in 2015. In the body of TEPAV (The Economic Research Foundation of Turkey), he consulted for the strategic vision project for Gaza urban strip which was proposed both to the Israeli and Palestinian authorities in January 2016. Since his return to Turkey in 2014, he has been a jury member in a series of national and international design competitions. 